\title{
ASO Author Reflections: Predicting Postoperative Resolution of Hypertension in Primary Hyperaldosteronism
}

\author{
Praveen D. Chatani, MD (1), Dana A. Dominguez, MD, and Naris Nilubol, MD \\ Surgical Oncology Program, National Cancer Institute, National Institutes of Health, Bethesda, MD
}

\section{PAST}

While hypokalemia routinely normalizes after unilateral adrenalectomy for primary hyperaldosteronism (PA), only one-third of patients will achieve postoperative normotension, and our ability to preoperatively identify those who will become normotensive remains both a priority and a point of much contention. Clinical nomograms such as the Aldosterone Resolution Score (ARS) or the Primary Aldosteronism Surgical Outcome (PASO) score have demonstrated 75-80\% accuracy in predicting complete clinical cure of hypertension (ccHTN), while adrenal venous sampling (AVS) provides biochemical confirmation of unilateral disease, thereby identifying patients who are likely to respond to adrenalectomy. ${ }^{1,2}$ To date, there has been limited conjunctive study of clinical and biochemical prognosticators.

\section{PRESENT}

Our single-institution analysis of patients who underwent AVS followed by unilateral adrenalectomy for PA is the first to evaluate factors associated with ccHTN while controlling for both clinical and biochemical variables. ${ }^{3}$ In our multivariable model, while an ARS score $\geq 4$ remained a strong predictor of ccHTN, with $60 \%$ of patients achieving ccHTN, suppression of the contralateral adrenal gland did not independently predict postoperative normotension after unilateral adrenalectomy. This study validates the importance of preoperative clinical

(C) This is a U.S. government work and not under copyright protection in the U.S.; foreign copyright protection may apply 2021

First Received: 9 February 2021

Accepted: 9 February 2021;

Published Online: 15 March 2021

N. Nilubol, MD

e-mail: niluboln@mail.nih.gov characteristics in identifying patients most likely to benefit from surgery and joins a number of others demonstrating the limited utility of contralateral suppression in AVS.,5

\section{FUTURE}

Our study does not assess the conditional utility of contralateral suppression as a prognosticator after unilateral adrenalectomy for PA. While there may very well be a time and place in patient selection for every biochemical index garnered by AVS, these data may well be the final "nail in the coffin' for the consideration of contralateral suppression in allcomers with PA. Studies that seek to improve upon existing nomograms should focus on furthering our understanding of the relationship between clinical and biochemical variables as it pertains to a careful selection of ideal operative candidates.

\section{REFERENCES}

1. Burrello J, Burrello A, Stowasser M, et al. The primary aldosteronism surgical outcome score for the prediction of clinical outcomes after adrenalectomy for unilateral primary aldosteronism. Ann Surg. 2020;272(6):1125-32.

2. Zarnegar R, Young WF Jr, Lee J, et al. The aldosteronoma resolution score: predicting complete resolution of hypertension after adrenalectomy for aldosteronoma. Ann Surg. 2008;247(3):511-8.

3. Dominguez DA, Chatani PD, Murphy R, et al. Contralateral suppression index does not predict clinical cure in patients undergoing surgery for primary aldosteronism. Ann Surg Oncol. 2021. https://doi.org/10.1245/s10434-021-09692-7.

4. Monticone S, Satoh F, Viola A, et al. Aldosterone suppression on contralateral adrenal during adrenal vein sampling does not predict blood pressure response after adrenalectomy. J Clin Endocrinol Metab. 2014;99(11):4158-66.

5. Tagawa M, Ghosn M, Wachtel $\mathrm{H}$, et al. Lateralization index but not contralateral suppression at adrenal vein sampling predicts improvement in blood pressure after adrenalectomy for primary aldosteronism. J Hum Hypertens. 2017;31(7):444-9.

Publisher's Note Springer Nature remains neutral with regard to jurisdictional claims in published maps and institutional affiliations. 